\title{
CULTURE IN A CUP. CHINESE TEA HERITAGE AND TOURISM
}

\author{
Irena Weber \\ University of Primorska, \\ Faculty of Tourism Studies - Turistica, \\ Portorož, Slovenia
}

\begin{abstract}
:
Tea is arguably one of the most widely consumed beverages in the world. It has been imbued with diverse medicinal, cultural and symbolic characteristics. Tea plays a significant role in the construction of contemporary national and regional identities that are in turn presented and represented for tourists in form of tea houses, museums, tea trails, guided tours and tea tasting. Based on ethnographic participant observation in Shanghai, Hangzhou, Taipei, and Pinglin the paper tackles a comparative analysis of tea culture as used and represented in cultural tourism, focusing on identity narratives of specialized tea museums, tea houses and tea ceremonies in order to show diverse identity and cultural construction based on particular historical circumstances.
\end{abstract}

\section{Keywords:}

tea heritage, tourism, China, Taiwan, identity

\section{INTRODUCTION}

Tea is arguably one of the most widely consumed beverages in the world. It has been imbued with diverse medicinal, cultural and symbolic characteristics. Few commodities have had such complex history and global impact. However it has been only recently that tourism studies have engaged in tackling the subject. The current presentation offers a cursory overview of historical underpinnings of tea production, consumption, and cultural heritage within the relevant tourism discourse and practices (Fig.1). Based on ethnographic participant observation in mainland China and Taiwan and tourism literature review, it tentatively indicates possible future research.

Figure 1. Tea tasting at Shanghai tea market

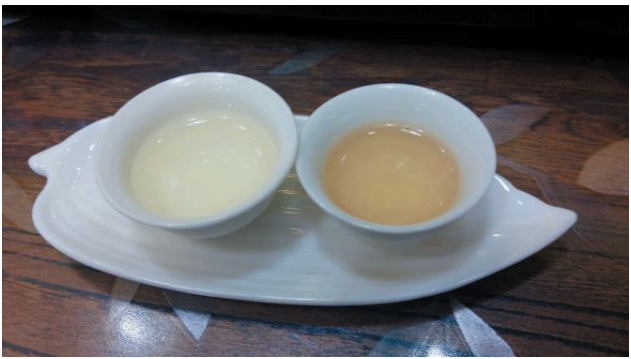

Photo: author 
Regardless of the type and style of writing, a popular (Wang, 2013), a semi-academic (Tong, 2010, Saberi, 2010), or academic (Benn, 2015, Kin Han, 2007), all accounts of the history of tea in China start with the Shen Nong (also transliterated as Shennong), a mythical ruler, heroic and cultural figure that was supposed to rule between 2737-2697 BCE. He is attributed to discover the beneficial effects of tea by chance, when one day the wind blew a leaf into his cup of hot water. Referred to as a Divine Husbandman, a father of agriculture and herbal medicine he is portrayed with a transparent stomach that enabled him to see which ingested plants were beneficial and which not. In Pinglin tea museum in Taiwan he appears as an animated figure that serves as a prop for tourist guides.

Cultivation of tea in China is usually traced to the mountainous southwest of Sichuan and Yunnan, although written records are not completely reliable due to uses of diverse characters depicting tea in different historical periods (Fig. 2).

Figure 2. Evolution of Chinese characters depicting TEA, China national tea museum, Hangzhou

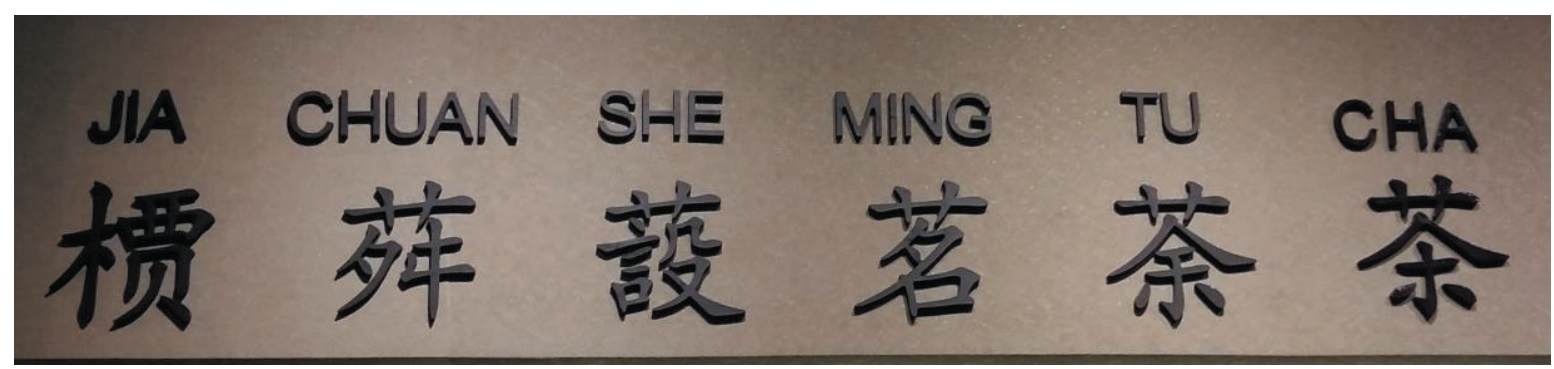

Photo: author

It was not before the Tang dynasty (7th-10th century) that the cha character was introduced and was since then unambiguously used to describe tea. It was also in the Tang dynasty that the first official book on tea was written around 780, by Lu Yu, entitled Cha Jing, usually transliterated as The classic of tea. Lu Yu is celebrated as the "sage of tea" or even the "god of tea" (Tong, 2010). His statues are found at tea museums and tea markets. He always appears good spirited, holding a cup of tea and a scroll with the tea pot and some rock placed at his feet.

His three volume book on tea consists of the writing on the origin and characteristics of tea, production and tools, preparation and utensils. It also includes anecdotes, legends, fables and recipes. Lu Yu effectively mixed historical accounts with literature that flourished in Tang dynasty and established the connection between the art of tea and the Arts including calligraphy, that is being revitalized at present (Fig. 3).

In time of the Song dynasty (10th-13th century) sophisticated new rules were introduced into the art of tea and it is from this period that the Japanese Cha No Yu ritual was developed and elaborated. In the Ming dynasty (14th -17th century) compressed tea was banned and loose leaf tea was prepared in a bowl (gaiwan) or in a pot thus underlying the importance of utensils. The whole new economy of tea pot production stems from this period. The styles of production and processing remained a closely guarded secret throughout Qing dynasty up to 1850 s when situation changed dramatically.

In 1848 a Scottish gardener and botanist Robert Fortune was send to the interior of China by the East India Company as a plant hunter and a spy with a sole mission to bring back the specimens and seeds of tea plant together with detailed notes on tea production and processing. He was disguised as a mandarin supposedly coming from beyond the Great wall (Rose, 2010). He negotiated with the Chinese intermediaries from the areas where tea was produced. The outcome of his mission - successful from the point of view of the British empire - has shifted the relationship between China and Britain and not only reshaped the map of tea production from China to India, but plunged China into a great economic crisis at the time. The Chinese production of tea hasn't truly picked up till a century later. 
While there is no singular linear history of tea in China, there are different periods, diverse schools and practices, numerous changes and ruptures, the official discourse on tea heritage tends to smooth all the wrinkles. A short, broad and vague, though decidedly friendly description of tea history is offered on the introductory wooden panel in the China national tea museum in Hangzhou, opened in 1991, and reads as follows: "Tea is one of China's major contributions to mankind and world civilization. China is the origin of the tea tree and the first country to discover and use tea. The tea industry and tea culture started from the drinking of tea. Over thousands of years, as the custom of drinking tea penetrated more and more deeply into Chinese people's lives, tea culture has been steadily enriched and developed as part of the age-old national culture and a gem of traditional oriental culture. Today, as a worldwide beverage, tea serves as a tie of deep affection between the Chinese and people in other parts of the world.".

Figure 3. Tea and caligraphy: video presentation at Shanghai tea market

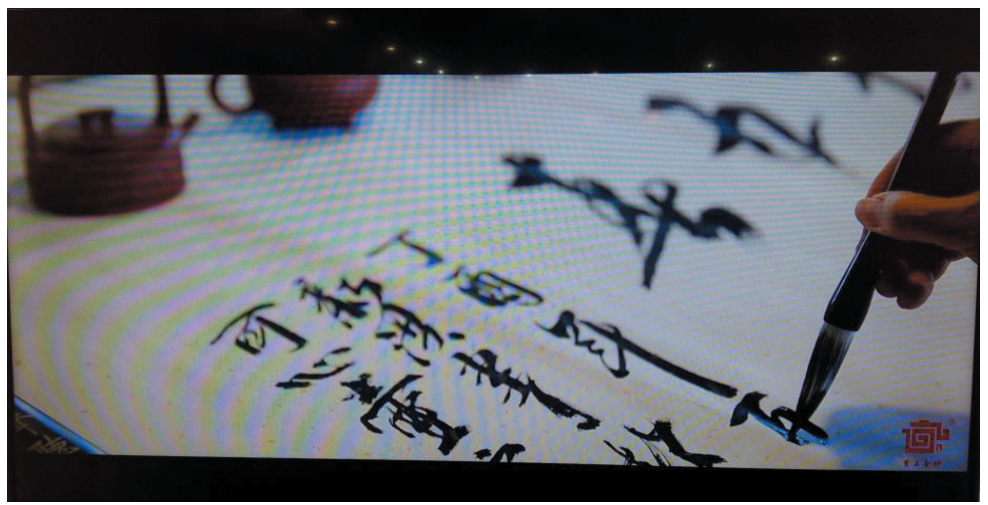

Photo: author

\section{TEA CLASSIFICATIONS}

Tea plant, either in form of a tree or a bush, belongs to the Camellia family and is classified as Camellia sinensis with two varieties that are commercially produced: Camelia sinensis sinensis from China and Camellia sinensis assamica from India.

All names for tea stem from Chinese characters, either cha or t'e. In most western languages it is a t'e varieties influenced by the Dutch historical involvement in the tea trade.

- Dutch: thee

- English: tea

- French: thé

- Spanish: té

- German: tee

Exception

- Portoguese: chá

In the East the cha variety is used:

- Russian: чай/ chai

- Serbian: чаj

- Slovenian: čaj

- Turkish: çay

- Persian: جاى / cha

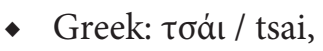

- Arabic: شان / shay 
In everyday use the word does not necessarily refer to Camellia sinensis but is more broadly used to include numerous varieties of herb infusions which strictly speaking shouldn't be referred to as tea though this standpoint is considered purists by some authors (Ellis et al., 2015).

Varieties of tea by color are result of different production procedures. Contemporary classification of tea usually includes distinction by fermentation, shape, baking and season. Fermentation is an expression borrowed from the wine production and is in fact a misnomer (Needham, 2000). The process that plucked tea leaves undergo is one of oxidation not fermentation. The only exception is Cinese $P u E r$ tea that is subjected to natural fermentation by Aspergillus niger, yeast bacteria that thrives in warm, dump and ventilated atmosphere. Natural fermentation takes up to 5 years. In most contemporary $P u E r$ production the process is artificially speeded up from 45 to 90 days (Zhang, 2014).

The shape of tea, such as string, sphere, flat or rolled depends on the manufacturing. The baking refers to heat application to the plucked leaves that may come from natural sun heat or several variety of artificial heat. There is no set season division for tea plucking but depends on a region or even on individual tea garden. It may be plucked just once a year for a few days or four or more times a year. It depends much like wine, on the complex concept of terroir.

\section{TEAAND TOURISM: AN EMBODIED EXPERIENCE AND CONSTRUCTION OF NATIONAL IDENTITIES}

In a seminal work on Tea and Tourism Jolliffe (2007, p.250) proposed a set of objectives for a research agenda that included understanding tea cultures and traditions in relation to tourism and cultural change, study of tea tourism products, demographics of tea tourists, their motivation and experience, studies of the nature tea destinations, preservation of tea material culture, sustainable tea tourism projects of various kinds. After the literature review in English it appears that such broad objectives are as yet far from being addressed although there are some indications that tea research is very much alive and strong in Chinese language (Benn, 2015).

In English, the most accessible lingua franca in academic sphere, research on tea is scattered at best (Xiao, 2017, Writer, 2013) and some essential ethnographic work has been done by the same scholar (Zhang, 2014, 2018a, 2018b).

Based on a relatively short ethnographic participant observation in China and Taiwan that was connected to topical conferences and Erasmus teaching, without any in-depth fieldwork, few observations on tea museums, tea markets, teahouses and teaware may be offered nonetheless. Conducting research in mainland China and Taiwan without the command of the language is of limited degree. Either one needs a mediator and interpreter or is reduced to body language and observation. There are some indications though that the younger generations both in mainland China and Taiwan are increasingly broadening their command of English particularly those living in cities but also frequented tourist spots.

Two tea museums both constructed in 1990s are observed in comparison. The one in mainland China was visited in May 2018, the one in Taiwan in March 2013, the same applies to teahouses and tea markets.

\section{Hangzhou, China}

In 1991 the National tea museum was opened in Hangzhou, among the fields of revered Long Jing green tea. This is the UNESCO world heritage area of the West lake where culture and particularly poetry is sedimented and mixed with the art of tea practices from different historical periods. Museum collection is divided into several houses each with its themes and topics. Despite the all encompassing essentialism at the beginning of the museum historical explanations - mentioned already above - there is a comprehensive overview of historical styles, customs and ritual uses of tea among different ethnic groups presented in writing, material culture, installations and videos. All written explanations are transliterated to English while the staff, polite and friendly do not communicate in English with a noted exception of a very young boy of ten or so, who was able to explain in fluent English, the background of the teaware on display and for sale in one of the houses. It was however quite easy to do a self guided tour while three buses of Italian tourist visiting at the same time 
had their own guide who spoke Italian. Tea tasting was offered to groups of Chinese families and appeared to be much more informal then at tea markets. Another tea tasting for larger groups of guided tourist was offered in a tent at the edge of the museum. After a short reflection I have decided not to participate in a group tasting, taking advice from the famous Song dynasty calligrapher Cai Xiang who in 1051 wrote the second specialist book on tea after $\mathrm{Lu} \mathrm{Yu}$, entitled A record of Tea or Cha Lu (Tong 2010). In the book he makes a following observation on the number of people partaking in tea: "The fewer guests when drinking tea the better. A crowd of guests is noisy and noise detracts from the elegance of the occasion. Drinking tea alone is serenity, with two guests is superior, with three or four is interesting, with five or six is extensive and with seven or eight is an imposition" (Jian, 2013, p.62).

\section{Pinglin, Taiwan}

Pinglin tea museum in Taiwan was opened in 1997 and is located by the Beishi river, in New Taipei city, an hour drive out of Taipei, under the mountains were green and oolong tea is produced. At the time of the visit I was the only visitor so the staff was very engaged in my well-being though none of them spoke English. While the history is comparably presented to the one in Hangzhou with some nuanced differences, the focus of presentation that is also laid out in several buildings is mainly on Taiwanese tea culture and particularly on the local ethnography of tea - with narratives and visual material on several generations of the same family tea producers in Pinglin. At the time one of the rooms was entirely dedicated to sensory experience, sound, sight, smell and taste of tea. In one of the buildings there was a tearoom with open windows to the river on the one side and the inner garden with water so the sound of water, essential to all Taiwanese teahouses may be heard along with a soft traditional music. The gong fu cha ceremony was prepared for me with the food of the midday (Fig. 4). The tea food menu was changed in accordance to the time of day so one dish can't be served all day long. The lady who performed gong fu cha explained - she had basic knowledge of English - that with high quality tea the locals didn't like to pour the first water over the teapot but prefer to be economical and mix the first and the second pour. I agreed this was a sensible thing to do so she poured me a mix. At the end she packed the remaining tea and offered me the whole box which I then drank sparingly at home during several months as the smell and color would vividly bring back the entire experience.

Figure 4. Food served with tea, teahouse at Pinglin tea museum Taiwan

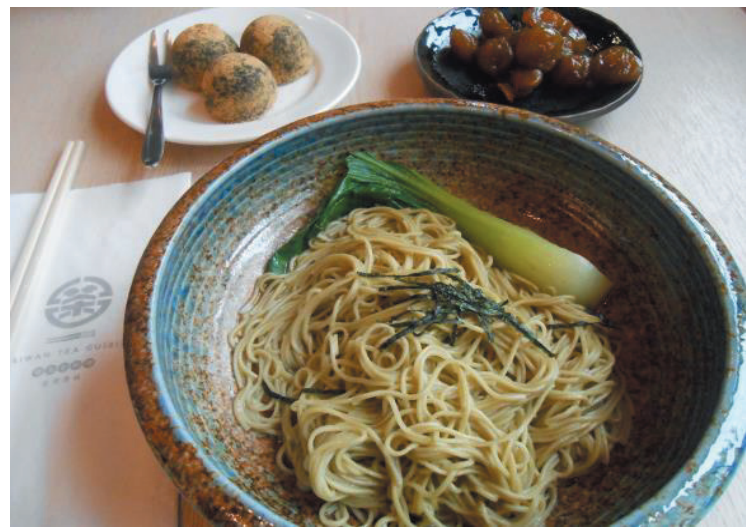

Photo: author

In her comparative research on mainland China and Taiwan Zhang (2018a) tackles the complex concept of authenticity and transnational flow and exchange of the art of tea. In mainland China the Taiwanese art of tea is sometimes regarded as the more authentic since it was not subjected to the period of Cultural revolution which had significant impact on traditional cultural practices including the art of tea. The teahouses were practically extinct at the time although Mao is said to have appreciated tea and was frequent visitor at the West 
Lake. The supposed authenticity of the Taiwanese practices are only recently being perceived as of value with the process of revitalization of cultural practices in mainland China, that are being in no small way influenced by tourist demands that search for "authentic" experiences.

The process of flow and borrowing however is subject to shifting rules, perceptions and practices both in traditional gong fu cha as well as in contemporary designer teahouses frequented mainly by the young urban population.

\section{CONCLUSION: CONTEMPORARY TRENDS AND FUTURE RESEARCH}

In its most recent report on the tea production and consumption FAO (2018) the tea production is set to increase $2,2 \%$ annually with green tea production increasing even more at a rate of $7,5 \%$ mainly due to promotion of health benefits. In stressing health aspects, the tea is in a sense coming back to its beginning, whether mythical or real when it was perceived as a plant mainly used for health reasons. On the other hand however two trends have been observed ethnographically: the contemporary combination of traditional and modern design in gong fu cha accessories at tea markets and the new street and teahouse design aimed at young population (Fig. 5) who demands trendy tea products both in mainland China and Taiwan. It is however a paradox that in Shanghai for instance one can't get green tea for breakfast. There is a coffee machine and low grade black tea in tea bags. There is also no green tea among the tea fields in Hangzhou. When asked in a hotel why is there no green tea the staff answered with a solemn expression: "European tourists drink coffee". There is at present a notable discrepancy between the official heritage promotion of tea in China and the lack of tea present in hotels which is worth exploring further. Several other strands of social sciences and humanities based research of tea and tea tourism may be proposed, such as contested processes of national identity and cultural heritage construction mediated by tourism discourse, research of embodied and sensory experience in tourism, tourism, art and design, language and image, power and responsible tourism. The contemporary local, national and global trends of young generations that include uses of tradition and heritage in newly shaped lifestyles also offers a new and potentially exciting research topic.

Tea as a plant, a beverage, heritage, experience and process should be further researched from multidisciplinary standpoints in order to expand the theoretical and applied knowledge of tourism and heritage studies.

Figure 5. Food served with tea, teahouse at Pinglin tea museum Taiwan.

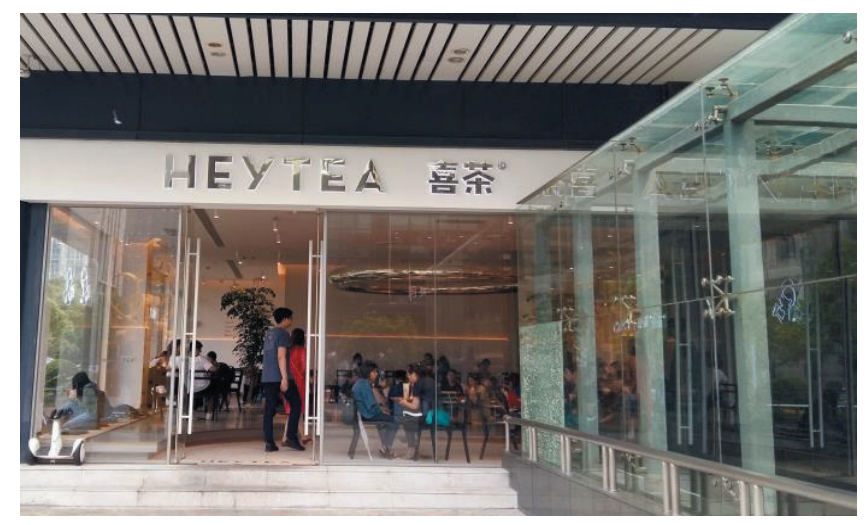

Photo: author 


\section{REFERENCES}

Benn, J. A. (2015). Tea in China: a Religious and Cultural History. Honolulu: University of Hawai'I Press.

Ellis, M., Coulton, R., \& Mauger, M. (2015). Empire of Tea. The Asian leaf that conquered the world. London: Reaktion Books.

FAO (2018). News Article: Global tea consumption and production driven by robust demand in China and India. Retrieved, September 12, 2018, from http://www.fao.org/news/story/en/item/1136255/icode/.

Jolliffe, L. (2007). Towards a Research Agenda for Tea Tourism. In Jolliffe, L. (Ed.), Tea and Tourism. Tourists, Traditions and Transformations (pp. 247-253). Clevedon: Channel View Publications.

Kin Han, P.L. (2007). Tracing the History of Tea Culture. In Jolliffe, L. (Ed.), Tea and Tourism. Tourists, Traditions and Transformations (pp. 23-37). Clevedon: Channel View Publications.

Needham, J. (2000). Science and Civilization in China. Volume 6. Biology and Biological Technology. Part V: Fermentations and Food Science by H.T. Huang. Cambridge: Cambridge University Press.

Rose, S. (2010). For All the Tea in China. Espionage, empire and the secret formula for the world's favourite drink. London: Arrow books.

Saberi, H. (2010). Tea. A Global History. London: Reaktion Books.

Tong, L. (2010). Chinese Tea. A Cultural History and Drinking Guide. Beijing:China Intercontinental Press.

Xiao, K. (2017). The taste of tea: Material, embodied knowledge and environmental history in northern Fujian, China. Journal of Material Culture, 22(1), 3-18. DOI:10.1177/1359183516633901.

Wang, J. (2013). All the tea in China. History, Methods and Musings. Shanghai: Betterl Link Press.

Writer, S. (2013). A World of Flavour: Taste and Text in Taiwanese Tea Culture. Media International Australia, 147, 134-146. Retrieved, September 12, 2018, from http://journals.sagepub.com/doi/abs/10.1177 /1329878X1314700114.

Zhang, J. (2014). Puer Tea. Ancient Caravans and Urban Chic. Seattle: University of Washington Press.

Zhang, J. (2018a). A Transnational Flow of the Art of Tea: The Paradox of Cultural Authenticity in Taiwan. The Asia Pacific Journal of Anthropology. 9 (1), 1-18. DOI:10.1080/14442213.2017.1400090.

Zhang, J. (2018b). Rituals, discourses, and realities: Serious wine and tea tasting in contemporary China. Journal of Consumer Culture, 1-19. DOI:10.1177/1469540518773812. 